\title{
Article \\ Reproducibility of Aerobic Granules in Treating Low-Strength and Low-C/N-Ratio Wastewater and Associated Microbial Community Structure
}

\author{
Hongxing Zhang ${ }^{1}$, Yong-Qiang Liu ${ }^{2}$, Shichao Mao ${ }^{1}$, Christain E. W. Steinberg ${ }^{3} \mathbb{D}$, Wenyan Duan ${ }^{1}$ \\ and Fangyuan Chen ${ }^{1, *}$ \\ 1 Yunnan Key Lab of Soil Carbon Sequestration and Pollution Control, \\ Faculty of Environmental Science and Engineering, Kunming University of Science and Technology, \\ Kunming 650500, China; hong_xing2207080@126.com (H.Z.); mscsuperman123@163.com (S.M.); \\ duanwenyan0405@gmail.com (W.D.) \\ 2 Faculty of Engineering and Physical Sciences, University of Southampton, Southampton SO17 1BJ, UK; \\ y.liu@soton.ac.uk \\ 3 Institute of Biology, Faculty of Life Sciences, Humboldt Universität zu Berlin, 10117 Berlin, Germany; \\ christian_ew_steinberg@web.de \\ * Correspondence: chenfy@kust.edu.cn
}

check for updates

Citation: Zhang, H.; Liu, Y.-Q.; Mao, S.; Steinberg, C.E.W.; Duan, W.; Chen, F. Reproducibility of Aerobic Granules in Treating Low-Strength and Low-C/N-Ratio Wastewater and Associated Microbial Community Structure. Processes 2022, 10, 444. https://doi.org/10.3390/pr10030444 Academic Editor: Francesca Raganat

Received: 18 January 2022

Accepted: 18 February 2022

Published: 23 February 2022

Publisher's Note: MDPI stays neutral with regard to jurisdictional claims in published maps and institutional affiliations.

Copyright: (C) 2022 by the authors. Licensee MDPI, Basel, Switzerland. This article is an open access article distributed under the terms and conditions of the Creative Commons Attribution (CC BY) license (https:// creativecommons.org/licenses/by/ $4.0 /)$.

\begin{abstract}
Long-term stability of the aerobic granular sludge system is essentially based on the microbial community structure of the biomass. In this study, the physicochemical and microbial characteristics of sludge and wastewater treatment performance were investigated regarding formation, maturation, and long-term maintenance of granules in two parallel sequencing batch reactors (SBR), R1 and R2, under identical conditions. The aim was to explore the linkage between microbial community structure of the aerobic granules, their long-term stability, as well as the reproducibility of granulation and long-term stability. The two reactors were operated with a COD concentration of $400 \mathrm{mg} / \mathrm{L}$ and a chemical oxygen demand to nitrogen (COD/N) ratio of 4:1 under anoxic-oxic conditions. It was found that although $\mathrm{SVI}_{30}$, sludge size, and distributions in $\mathrm{R} 1$ and $\mathrm{R} 2$ were different, aerobic granules were formed, and they maintained long-term stability in both reactors for 320 days, implying that a certain level of randomness of granulation does not affect the long-term stability and performance for COD and $\mathrm{N}$ removal. In addition, a significant reduction in the richness and diversity of microbial production was observed after the sludge was converted from inoculum or flocs to granules, but this did not negatively affect the performance of wastewater treatment. Among the predominant microbial species in aerobic granules, Zoogloea was identified as the most important bacteria present during the whole operation with the highest abundance, while Thauera was the important genus in the formation and maturation of the aerobic granules, but it cannot be maintained long-term due to the low food-to-microorganisms ratio (F/M) in the system. In addition, some species from Ohtaekwangia, Chryseobacterium, Taibaiella, and Tahibacter were found to proliferate strongly during long-term maintenance of aerobic granules. They may play an important role in the long-term stability of aerobic granules. These results demonstrate the reproducibility of granulation, the small influence of granulation on long-term stability, and the robustness of aerobic granulation for the removal of COD and N. Overall, our study contributes significantly to the understanding of microbial community structure for the long-term stability of aerobic granular sludge in the treatment of low-COD and low-COD/N-ratio wastewater in practice.
\end{abstract}

Keywords: aerobic granular sludge; microbial community structure; reproducibility; low-strength $\mathrm{COD}$; low $\mathrm{COD} / \mathrm{N}$ ratio

\section{Introduction}

Aerobic granules are dense and compact aggregates immobilized by microorganisms themselves without a carrier medium. Due to the high compactness and large size, the 
aerobic granules have high settling capacity, biomass retention, and tolerance to toxic and shock loads during treatment of various wastewaters. However, aerobic granular sludge is still far from widespread in practice due to a concern of low stability in long-term operation, during which the main reasons for the instability of aerobic granules could be core hydrolysis [1,2], overgrowth of filament bacteria [3,4], and reduction in the excretion of functional extracellular polymer substrates [5]. In recent years, many efforts have been made to address this problem, but it remains a challenge because the factors involved are interrelated, manipulation capabilities are limited, and trials for long-term studies are very time-consuming. The stability of the aerobic granules in practice still needs to be investigated thoroughly.

The stability of aerobic granular sludge is essentially determined by the structure of microbial populations residing in granules, such as predominant bacteria groups, the richness and diversity of microbial community, and microbial dynamics in response to operational and environmental changes in wastewater treatment. The structure of microbial populations in aerobic granules is greatly dependent on influent wastewater compositions, operation parameters, and environmental conditions. For example, Cydzik-Kwiatkowska et al. (2015) found that the bacterial structure of aerobic granules is significantly affected by the aeration mode and nitrogen loading in a nitrogen removal system [6]. Specifically, Swiatczak et al. (2018) proved that the variables, i.e., temperature, time of aerobic granular sludge adjustment at start-up, and reactor conditions, contributed $92.3 \%$ to the variability of the microbial community of a full-scale granular sludge system [7]. However, all the above adjustable factors cannot be used to directly and precisely regulate the microbial structure, because some uncontrollable factors due to theoretical and technical limitations, such as size distribution, biomass growth, and microenvironment in aerobic granules, also affect the microbial structure. The growth of microbial species inside the aerobic granules is controlled by the microenvironment, which is affected by the granule size, compactness, and other physical properties of the granules, resulting in different performances and stabilities of the aerobic granules during the long-term operation period, even under the same operating conditions. Currently, there is limited information on the effects of these uncontrollable conditions on the microbial community in aerobic granular sludge, which hinders a deep understanding and effective control of the aerobic granular sludge system for long-term stable operation. Cultivation of aerobic granules using feeds with high ammonia concentration and low carbon-to-nitrogen $(\mathrm{C} / \mathrm{N})$ ratio under anoxic-oxic conditions has been proven to be effective in increasing the stability of aerobic granules [8]. The high ammonia concentration favors the enrichment and accumulation of slow-growing nitrifying bacteria in the granules, while the anoxic-oxic conditions inhibit the overgrowth of ordinary heterotrophic organisms (OHO) to promote floc formation [9]. Liu et al. (2004) reported that the nitrifying granules at a $\mathrm{C} / \mathrm{N}$ ratio of $100 / 30$ had the smallest average size, i.e., about $0.3 \mathrm{~mm}$, compared to the other granules cultured at higher $\mathrm{C} / \mathrm{N}$ ratios [10]. Cha et al. (2021) reported that the mean size of aerobic granules in the system with a $\mathrm{C} / \mathrm{N}$ of 4 was less than $0.5 \mathrm{~mm}$ during operation for over 300 days [8]. It has also been reported that the diffusivity of the substrate directly affects microbial competition for the substrate and thus granulation [11,12]. When the size of the aerobic granules is less than $0.7 \mathrm{~mm}$, the substrate and oxygen distribute more evenly in the granules than in the large granules because the mass transfer resistance is lower due to the size [13]. Therefore, it could be assumed that the microbial population structure in smaller aerobic granules is mainly affected by the population of microorganisms and their mutual interactions, rather than by the physical properties of the granules such as size and compactness. This would greatly simplify the mechanism of microbial community formation and facilitate the understanding of microbial development in practical aerobic granule applications.

In this study, aerobic granular sludge treating synthetic wastewater with COD of $400 \mathrm{mg} / \mathrm{L}$ and ammonia nitrogen of $100 \mathrm{mg} \mathrm{N} / \mathrm{L}$ under anoxic-oxic conditions was cultured to investigate the microbial structure of the aerobic granular sludge during the 
long-term operation period. During more than 300 days of operation, the wastewater treatment performance and the physical and microbial properties of the aerobic granules were monitored at selected stages. The specific objective of this study was to characterize the relationships between the performance, microbial structure, and stability of the aerobic granular sludge during start-up, maturation, and continued long-term maintenance of the aerobic granular sludge operation. The results of the study provide insight into the key factors affecting the long-term stability of an aerobic granular system and clues for better control of the system in practical applications.

\section{Materials and Methods}

\subsection{Experimental Setup and Operation}

The experiment was carried out in two parallel bubble columns (R1 and R2) with an internal diameter of $5 \mathrm{~cm}$ and a working volume of $2 \mathrm{~L}$. The two reactors were operated sequentially with a cycle time of $4 \mathrm{~h}$, including $5 \mathrm{~min}$ of anaerobic feeding, $55 \mathrm{~min}$ of static condition without mixing, 145 to $170 \mathrm{~min}$ of aeration, 30 to $5 \mathrm{~min}$ of settling, and 5 min of effluent discharging. The feed was pumped into the reactors from the top port, while the effluents were discharged from the middle port of the reactor with a volumetric exchange ratio of $50 \%$. During the aeration phases, fine air bubbles were pumped into the reactors through an air sparger at the bottom of the reactors with a flowrate of $2 \mathrm{~L} / \mathrm{min}$. The inoculated activated sludge was collected from a local domestic wastewater treatment plant with a sludge volume index $\left(\mathrm{SVI}_{30}\right)$ of $106.2 \mathrm{~mL} / \mathrm{g}$. The experiment took place at a temperature ranging from 18 to $25^{\circ} \mathrm{C}$.

\subsection{Medium}

The influent was synthetic wastewater with compositions of $\mathrm{NaCH}_{3} \mathrm{COO},\left(\mathrm{NH}_{4}\right)_{2} \mathrm{SO}_{4}$, $\mathrm{KH}_{2} \mathrm{PO}_{4}, \mathrm{NaHCO}_{3}$, and micronutrients. $\mathrm{NaCH}_{3} \mathrm{COO}$ and $\left(\mathrm{NH}_{4}\right)_{2} \mathrm{SO}_{4}$ provided carbon and nitrogen sources, respectively, while $\mathrm{NaHCO}_{3}$ provided inorganic carbon and $\mathrm{pH}$ buffer for nitrification. The experiment was conducted in two stages: the first stage was from day 1 to 32 with influent concentrations of COD and $\mathrm{NH}_{4}{ }^{+}-\mathrm{N}$ of $400 \mathrm{mg} / \mathrm{L}$ and $50 \mathrm{mg} \mathrm{N} / \mathrm{L}$, respectively; while the second stage lasted from day 32 until the end of the operation, i.e., day 320, with influent concentrations of COD and $\mathrm{NH}_{4}{ }^{+}-\mathrm{N}$ of $400 \mathrm{mg} / \mathrm{L}$ and $100 \mathrm{mg} \mathrm{N} / \mathrm{L}$, respectively. With these compositions of synthetic wastewater, OLR was constant at $1.21 \mathrm{~kg} \mathrm{COD} / \mathrm{m}^{-3} \mathrm{~d}^{-1}$ during the two stages, while the ammonia loading rate increased from 0.15 to $0.3 \mathrm{~kg} \mathrm{~N} / \mathrm{m}^{-3} \mathrm{~d}^{-1}$ from the first to the second stage. $\mathrm{pH}$ was controlled in the range of 7.5-8.5 during the whole operation period. Micronutrients were supplied: $\mathrm{CaCl}_{2} \cdot 2 \mathrm{H}_{2} \mathrm{O} 25 \mathrm{mg} / \mathrm{L}, \mathrm{MgSO}_{4} \cdot 7 \mathrm{H}_{2} \mathrm{O} 20 \mathrm{mg} / \mathrm{L}, \mathrm{FeSO}_{4} \cdot 7 \mathrm{H}_{2} \mathrm{O} 10 \mathrm{mg} / \mathrm{L}$, EDTA-2Na $10 \mathrm{mg} / \mathrm{L}, \mathrm{MnCl}_{2} \cdot 4 \mathrm{H}_{2} \mathrm{O} 0.12 \mathrm{mg} / \mathrm{L}, \mathrm{ZnSO}_{4} \cdot 7 \mathrm{H}_{2} \mathrm{O} 0.12 \mathrm{mg} / \mathrm{L}, \mathrm{CuSO}_{4} \cdot 5 \mathrm{H}_{2} \mathrm{O}$ $0.03 \mathrm{mg} / \mathrm{L},\left(\mathrm{NH}_{4}\right)_{6} \mathrm{Mo}_{7} \mathrm{O}_{24} \cdot 4 \mathrm{H}_{2} \mathrm{O} 0.05 \mathrm{mg} / \mathrm{L}, \mathrm{NiCl}_{2} \cdot 6 \mathrm{H}_{2} \mathrm{O} 0.1 \mathrm{mg} / \mathrm{L}, \mathrm{CoCl}_{2} \cdot 6 \mathrm{H}_{2} \mathrm{O} 0.1 \mathrm{mg} / \mathrm{L}$, $\mathrm{AlCl}_{3} \cdot 6 \mathrm{H}_{2} \mathrm{O} 0.05 \mathrm{mg} / \mathrm{L}$, and $\mathrm{H}_{3} \mathrm{BO}_{3} 0.05 \mathrm{mg} / \mathrm{L}$.

\subsection{Analytical Method}

$\mathrm{COD}, \mathrm{NH}_{4}{ }^{+}-\mathrm{N}, \mathrm{NO}_{3}{ }^{-}-\mathrm{N}, \mathrm{NO}_{2}{ }^{-}-\mathrm{N}, \mathrm{SVI}$, mixed liquor suspended solids (MLSS) and mixed liquor volatile suspended solids (MLVSS) were analyzed according to standard methods (APHA) [14]. Average particle size was determined by a laser particle size analysis system with a measuring range from 0 to $2000 \mu \mathrm{m}$ (Malvern MasterSizer Series 2600, Malvern Instruments Ltd., Malvern, UK). Morphometry of the aerobic granules was observed by an optical microscope equipped with a digital camera (Leica Microsystems Wetzlar GmbH.DM100.DEU, Wetzlar, Germany). Surface profile was evaluated by means of a scanning electron microscope (Hitachi SU-8010, Tokyo, Japan).

\subsection{Microbiological Analysis of Granular Sludge}

For biomolecular analyses of the microorganisms, sludge from the two reactors was collected at different days of operation and stored at $-80^{\circ} \mathrm{C}$. Sample DNA was extracted using a PowerSoil ${ }^{\circledR}$ DNA Isolation kit. The purity and concentration of the isolated 
DNA was measured by a Qubit2.0 DNA kit (Life Technologies, Carlsbad, CA, USA). The 515F/805R primer set (GTGCCAGCMGCCGCGGTAA/GACTACHVGGGTATCTAATCC) was used to amplify the V4 regions of the bacterial 16SrDNA gene. Amplification began with an initial denaturation at $95^{\circ} \mathrm{C}$ for $3 \mathrm{~min}$, followed by 5 cycles of denaturation at $94{ }^{\circ} \mathrm{C}$ for $20 \mathrm{~s}$, annealing at $55^{\circ} \mathrm{C}$ for $20 \mathrm{~s}$ and extension at $72{ }^{\circ} \mathrm{C}$ for $30 \mathrm{~s}$. It ended with a final extension step at $72{ }^{\circ} \mathrm{C}$ for $5 \mathrm{~min}$. The PCR products were then subjected to $1.8 \%$ agarose gel electrophoresis for detection. Samples with a bright main band of approximately $450 \mathrm{bp}$ were chosen and mixed in equidensity ratios. The mixture of PCR products was purified using a VAHTSTM DNA Clean Beads (Vazyme Biotech Co., Ltd., Nanjing, China). After quantification, the amplicons were sequenced using the MiSeq platform (Illumina, LA, USA). The sequences were validated by software cutadapt (version 1.2.1), pear (version 0.9.6) and Prinseq (version 0.20.4), among which low-quality sequences were treated by Prinseq. Chimeras were detected and removed by software Usearch (version 5.2.236) and identified by Uchime (version 4.2.40). An identity of $97 \%$ was adopted to cluster the normalized sequences into operational taxonomic units (OTUs), which were annotated based on the Silva taxonomic database. The diversity was assessed within a community ( $\alpha$-diversity) and was calculated and displayed with Mothur (Version 1.30.1). The Chao1, Shannon, and Simpson indices were analyzed according to Hill et al. [15], and the abundance-based coverage estimator (ACE) was analyzed according to Westphal et al. [16].

\section{Results and Discussion}

\subsection{Characteristics of Aerobic Granular Sludge during Long-Term Operation}

Figure 1 shows the morphology of sludge in R1 and R2, respectively, during the operation time. It can be seen that tiny aggregates appeared on day 30 in the two reactors and mixed with flocs. On day 79, the aerobic granules formed in R1 with clear-cut outlines and fewer flocs, while in R2 there were only small granules with a large number of flocs. On day 106, aerobic granules of similar size were present in both reactors and gradually developed into large and dense granules with small flocs by day 300. Figure 2 shows the surface morphometry of the aerobic granules in R1 and R2 examined by SEM. It can be seen that the surface of the aerobic granules with cocci, bacilli, and filaments are quite similar.

The size of aerobic granules throughout the whole operation is shown in Figure 3, which reveals a different development of granules in R1 and R2. The mean size of the aerobic granules in R1 increased with a large fluctuation, while that in R2 increased stably, until the end of the operation. In R1, the mean size of aerobic granules increased to $380 \mu \mathrm{m}$ on day 136, while it decreased to $276 \mu \mathrm{m}$ on day 240 , which was combined with variations in the settling ability of aerobic granules. On day 294, the size appeared to recover and increased to $462 \mu \mathrm{m}$. In R2, the mean size of aerobic granules gradually increased to $662 \mu \mathrm{m}$ on day 294. Meanwhile, the size distribution of aerobic granules was found to be highly variable, with a narrower size distribution in R1 than in R2. These discrepancies in the size development and morphometry of the sludge in R1 and R2 over time indicate that the formation and growth of aerobic granules are different even under seemingly identical operating conditions, suggesting some degree of randomness unrelated to the apparent operating conditions related to granule formation and development. In addition, it should be noted that the mean size of the aerobic granules in the two reactors was less than $700 \mu \mathrm{m}$, implying that the overall mass transfer resistance in the granules may be negligible. 


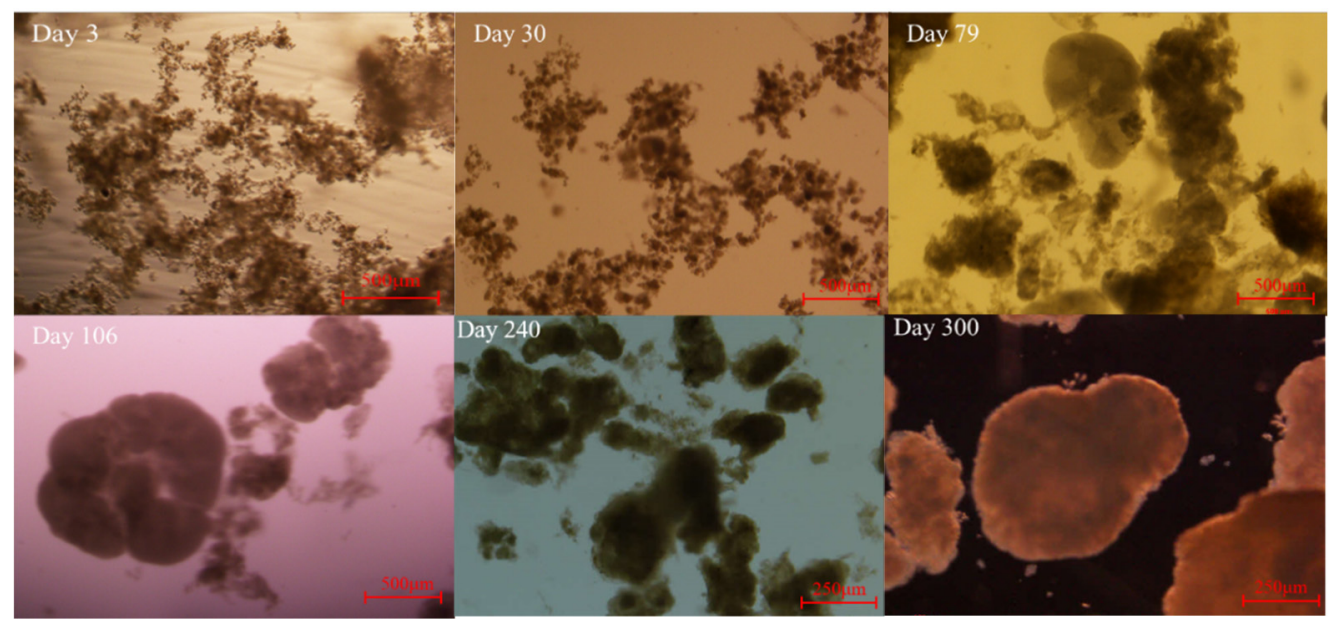

(A)

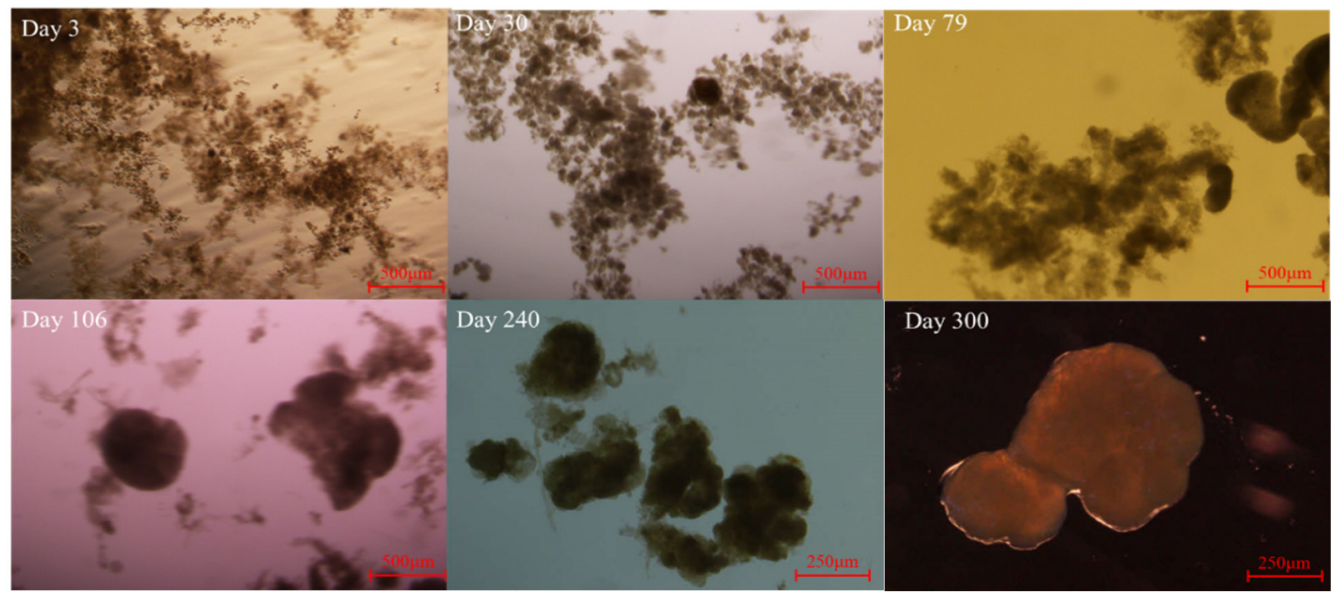

(B)

Figure 1. Morphology of the sludge on different days of the operation. (A) in R1; (B) in R2.

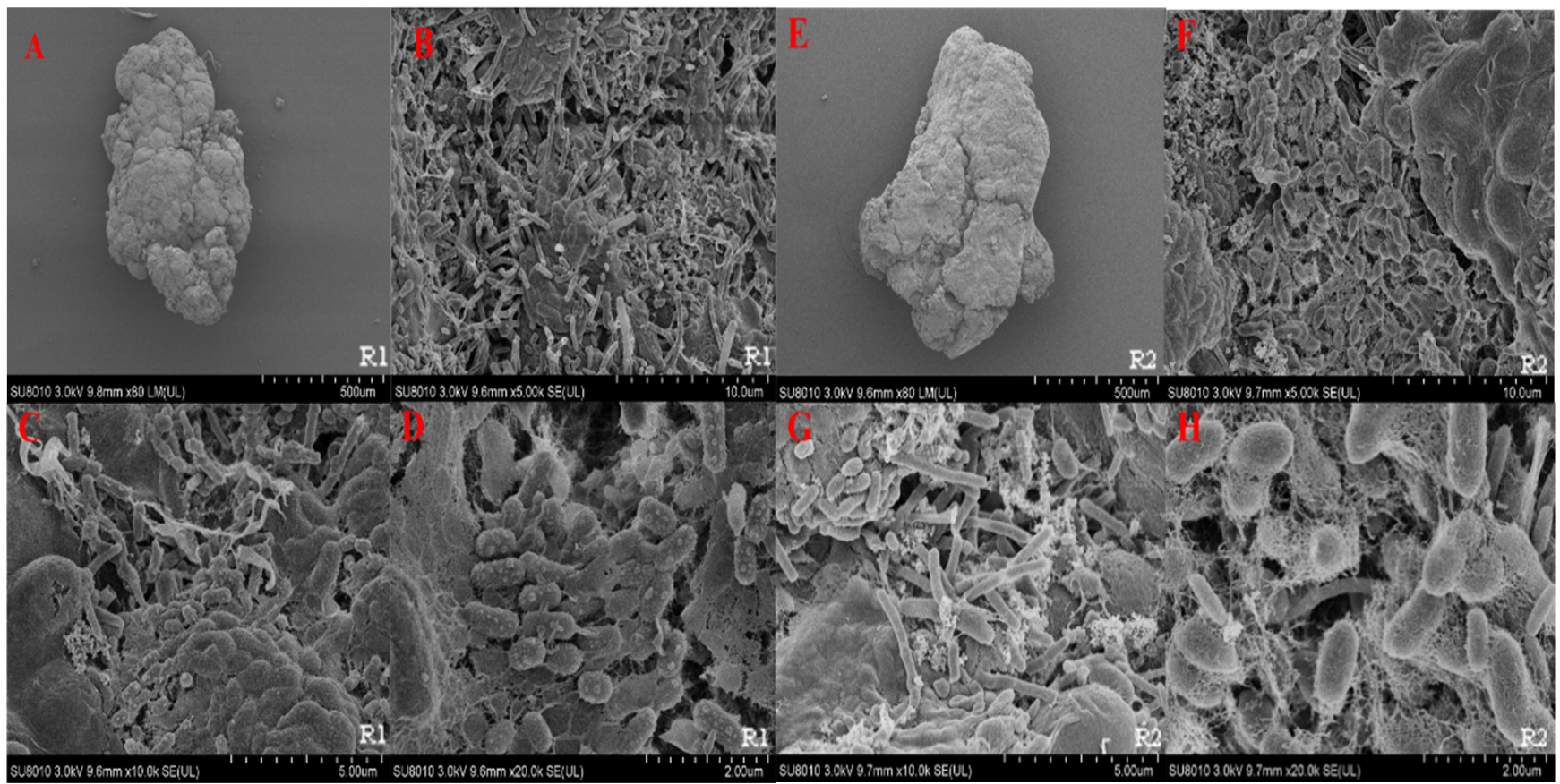

Figure 2. SEM of the aerobic granules in R1 and R2. (A-D), in R1; (E-H), in R2. 

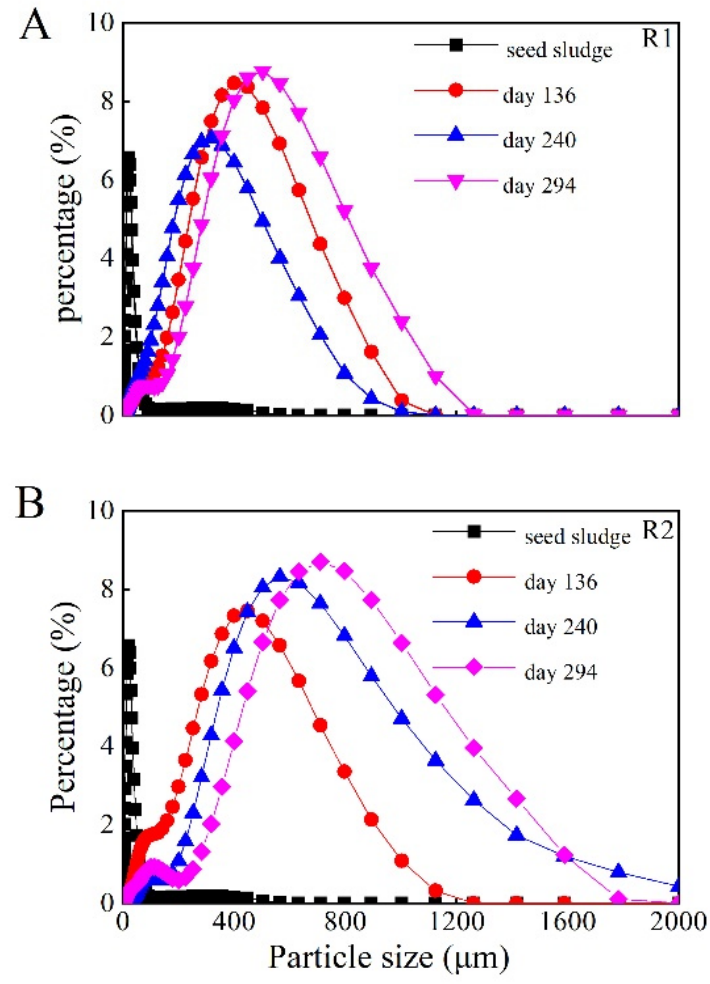

Figure 3. Size distribution and development of aerobic granules in R1 and R2 over the operating time. (A) R1; (B) R2.

SVI is normally used as a direct indicator of both sludge settling ability and aerobic granule stability. An $\mathrm{SVI}_{30}$ below $80 \mathrm{~mL} / \mathrm{g}$ is usually considered indicative of increased sludge stability with good settling ability. At the same time, the ratio of $\mathrm{SVI}_{30}$ to $\mathrm{SVI}_{5}$ close to 1 is often used as an indicator of aerobic granule dominance. Figure $4 \mathrm{~A}, \mathrm{~B}$ shows the development of SVI in R1 and R2 during the operating period. It can be seen that the sludge in both reactors was subject to large variations in settling ability and stability during the formation period, i.e., from the inoculation of the activated sludge to the formation of the aerobic granules. In $\mathrm{R} 1, \mathrm{SVI}_{30}$ decreased sharply in the first 20 days and then increased abruptly to $148.6 \mathrm{~mL} / \mathrm{g}$ within the next 20 days due to sludge bulking, indicating low settling ability and stability of the sludge. Thereafter, $\mathrm{SVI}_{30}$ began to decrease and reached $50 \mathrm{~mL} / \mathrm{g}$ on day 65, which was considered to be the time when a dominant aerobic granule formed in $\mathrm{R} 1$, as $\mathrm{SVI}_{30} / \mathrm{SVI}_{5}$ was close to 1 at this time. Similarly, $\mathrm{SVI}_{30}$ in $\mathrm{R} 2$ first decreased and then increased due to sludge bulking until day 90, showing a twofold increase and decrease. Thereafter, aerobic granules began to form in $\mathrm{R} 2$ with $\mathrm{SVI}_{30} / \mathrm{SVI}_{5}$ close to 1 .

After the formation of the aerobic granules in each reactor, the $\mathrm{SVI}_{30}$ remained in the range of $60-80 \mathrm{~mL} / \mathrm{g}$ until day 140 , which can be considered as the maturity stage of the aerobic granules in the two reactors. From day 140 to the end of the operation period on day 320, the $\mathrm{SVI}_{30}$ of the aerobic granules in both $\mathrm{R} 1$ and $\mathrm{R} 2$ remained around $40 \mathrm{~mL} / \mathrm{g}$, and no floc competition was observed, as reported by Liu et al. (2012) on the real wastewater treatment during the long-term operation period [17], demonstrating the high stability of the aerobic granules.

Again, the difference in the change of $\mathrm{SVI}_{30}$ in two identical reactors indicates some randomness of granule formation especially during the granule formation phase. In contrast to the size development of aerobic granules, it is noted that the settling ability and stability of aerobic granules in R1 and R2 were quite similar during maturation and long-term maintenance, regardless of the differences in the mean size and distribution of aerobic granules in the two reactors. This indicates that aerobic granules with different granule formation with respect to $\mathrm{SVI}_{30}$ can still achieve similar settling ability and stability after maturation. 

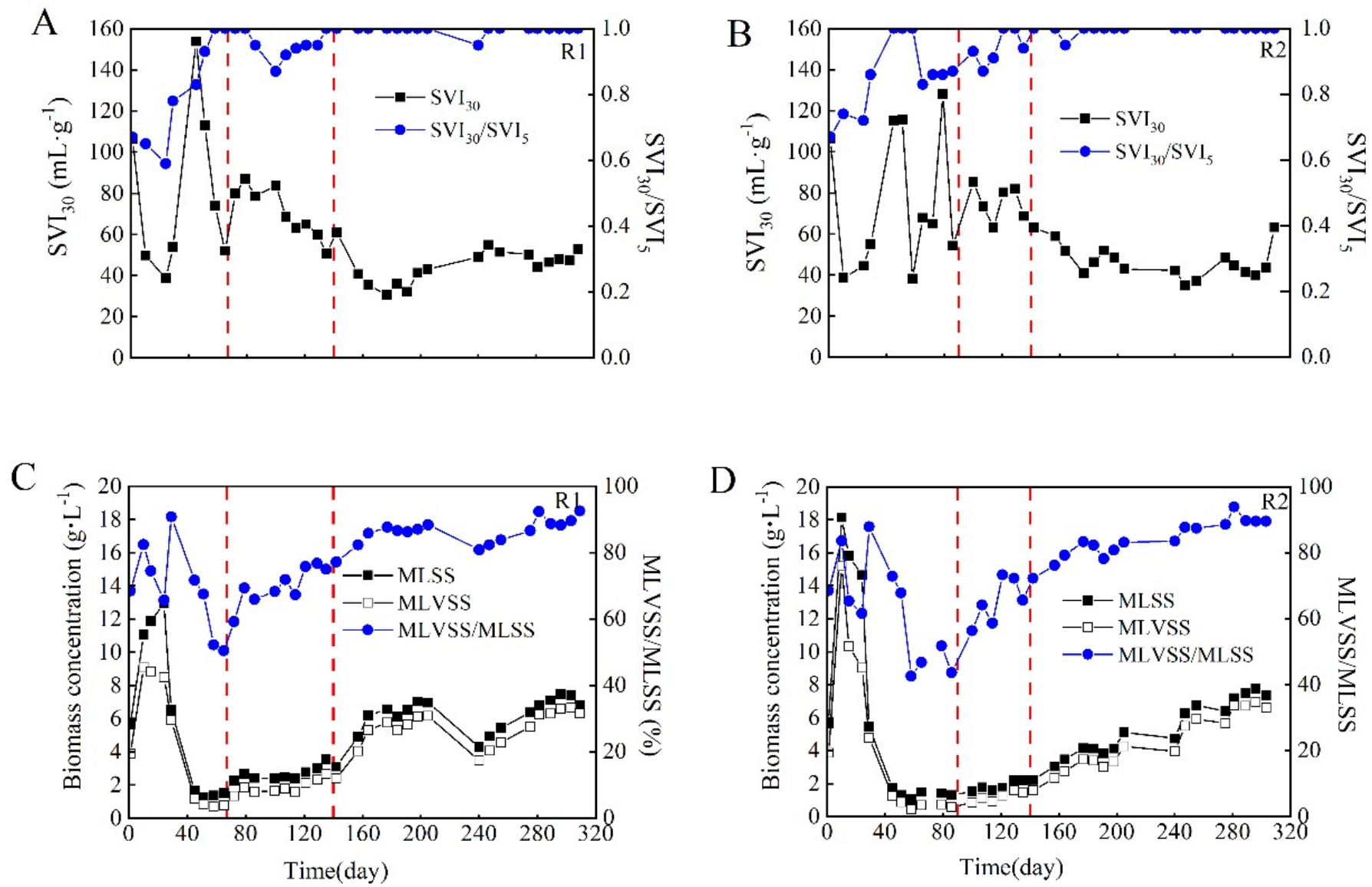

Figure 4. Profiles of SVI and MLSS during the operation period. (A,C), in R1; (B,D), in R2.

The biomass concentration, indicated by MLVSS/MLSS over the whole operation time, is shown in Figure 4C,D, which depicts the growth and accumulation of aerobic granules as a whole. MLSS in the two reactors initially decreased, stagnated at the lowest concentration after the granules had formed for a period of time, and increased again by the end of the operation. In R1, the MLSS gradually decreased from $5.6 \mathrm{~g} / \mathrm{L}$ of inoculum to $0.7 \mathrm{~g} / \mathrm{L}$ on day 58 , which was caused by the washout of the flocs due to the increased SVI and the shortened settling time. After this low MLSS was maintained for about 7 days, aerobic granules began to form and MLSS began to increase due to retention and growth of high-settling biomass. In R2, the only difference in MLSS development from R1 was that the low biomass period $(0.69 \mathrm{~g} / \mathrm{L})$ lasted longer, approximately 40 days. This was due to the longer sludge bulking and $\mathrm{SVI}_{30}$ fluctuating twice in $\mathrm{R} 2$, resulting in less biomass retention than in R1. After aerobic granules formed in R2 on day 90, MLSS began to increase. After the aerobic granules were formed in both reactors, the MLSS gradually increased to $6.8 \mathrm{~g} / \mathrm{L}$ in $\mathrm{R} 1$ and $5.1 \mathrm{~g} / \mathrm{L}$ in $\mathrm{R} 2$ at the end of the operation.

At the same time, it is observed that MLSS shows an inverse trend with SVI, i.e., lowest MLSS in the formation phase, slightly increased MLSS in the maturation phase, and further increased MLSS in the long-term maintenance of aerobic granules. The MLVSS can be used to detect the amount of microbial organisms in the biomass, which represents the organic composition of the MLSS. During the development of the aerobic granules, the MLVSS/MLSS changed according to the MLSS: it decreased from $80 \%$ to $60 \%$ and $50 \%$ in R1 and R2, respectively, after the formation of the aerobic granules, and then gradually increased to $80 \%$ in both reactors during the maturation of the aerobic granules. Subsequently, the MLVSS/MLSS remained in the range of $80-90 \%$ until the end of the operation, indicating high microbial richness and activity in the long-term maintenance of the aerobic granules in R1 and R2. 


\subsection{Performance of the Aerobic Granular Sludge during the Long-Term Operation Period}

Figure 5 shows the performance of the aerobic granules in R1 and R2, respectively. It can be seen that the COD removal efficiency in both reactors was above $90 \%$ throughout the operating period, although sludge bulking and extremely low biomass concentrations occurred in the first operating phase. This indicates that the heterotrophic microorganisms responsible for organic matter removal were very active in the aerobic granules to handle the added COD. In comparison, the efficiency of ammonium removal fluctuated when the aerobic granules were formed, which can be attributed to the low biomass concentration at the beginning due to the leaching of the nitrifying bacteria.
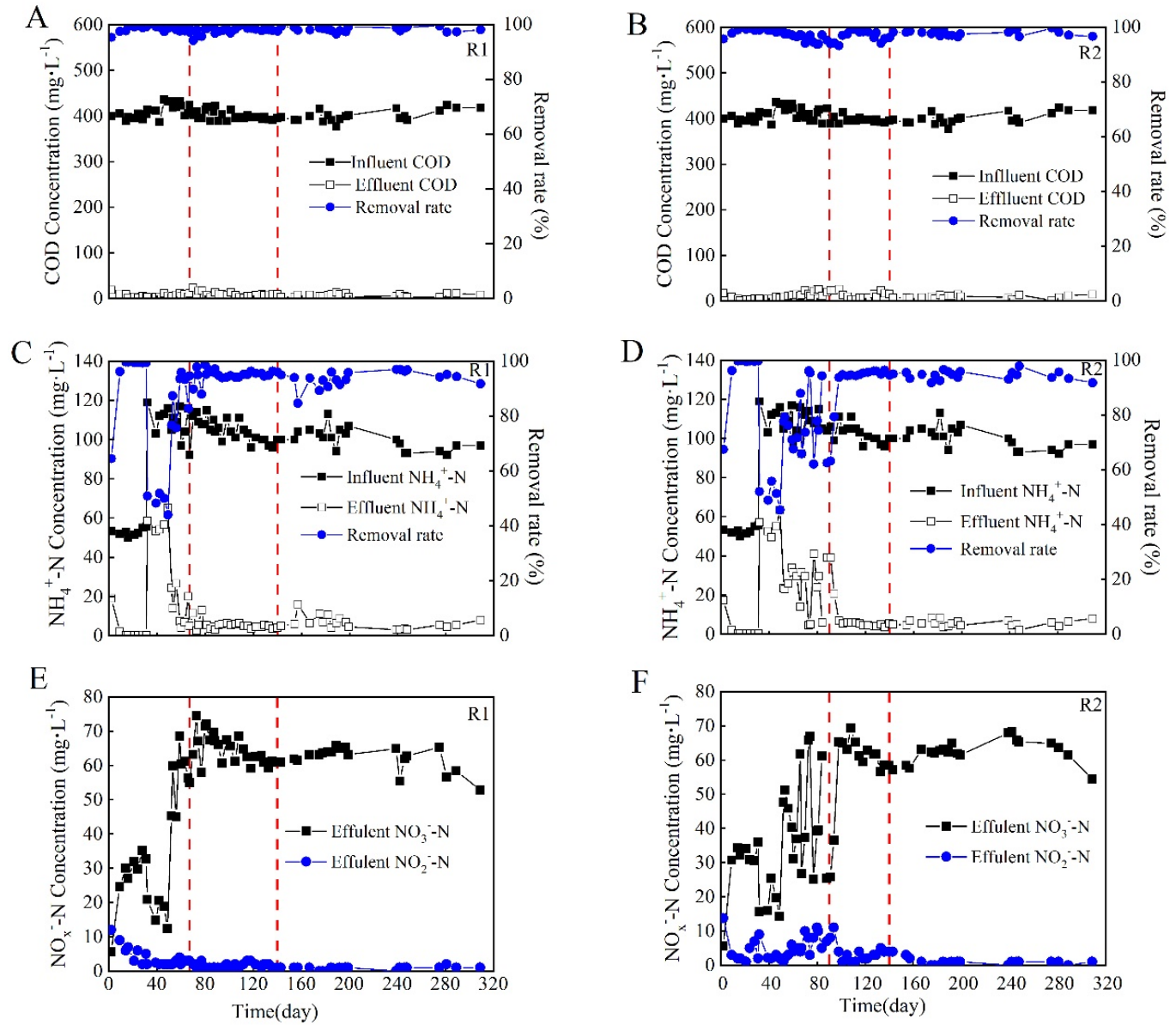

Figure 5. Performance of the aerobic granules over the operation period in R1 and R2. (A,B), COD removal in R1 and R2, respectively; (C,D), ammonium removal in R1 and R2, respectively; $(\mathbf{E}, \mathbf{F}), \mathrm{NO}_{X}$ formation in $\mathrm{R} 1$ and $\mathrm{R} 2$, respectively.

After the formation of aerobic granules in the two reactors, the ammonia removal efficiency increased to over $90 \%$ as the nitrifying bacteria in the granules re-accumulated with increasing biomass. Throughout the operating period, ammonium was mostly converted to nitrate in R1 and R2, except during the period of aerobic granule formation with fluctuations in ammonium removal. The similar performances of the aerobic granules in R1 and $\mathrm{R} 2$ indicate that the different average size and size distribution of the aerobic granules does not have a large effect on the ability to biodegrade when the granule size is smaller and there is no obvious mass transfer resistance. 


\subsection{The Richness and Diversity of Microbial Community in the Aerobic Granular Sludge}

The richness and diversity of the microbial population throughout the operating period are presented in Figure 6. The number of operational taxonomic units (OTUs), the abundance-based coverage estimator (ACE) index, and the Chao1 index are used to indicate the richness of the microbial population.
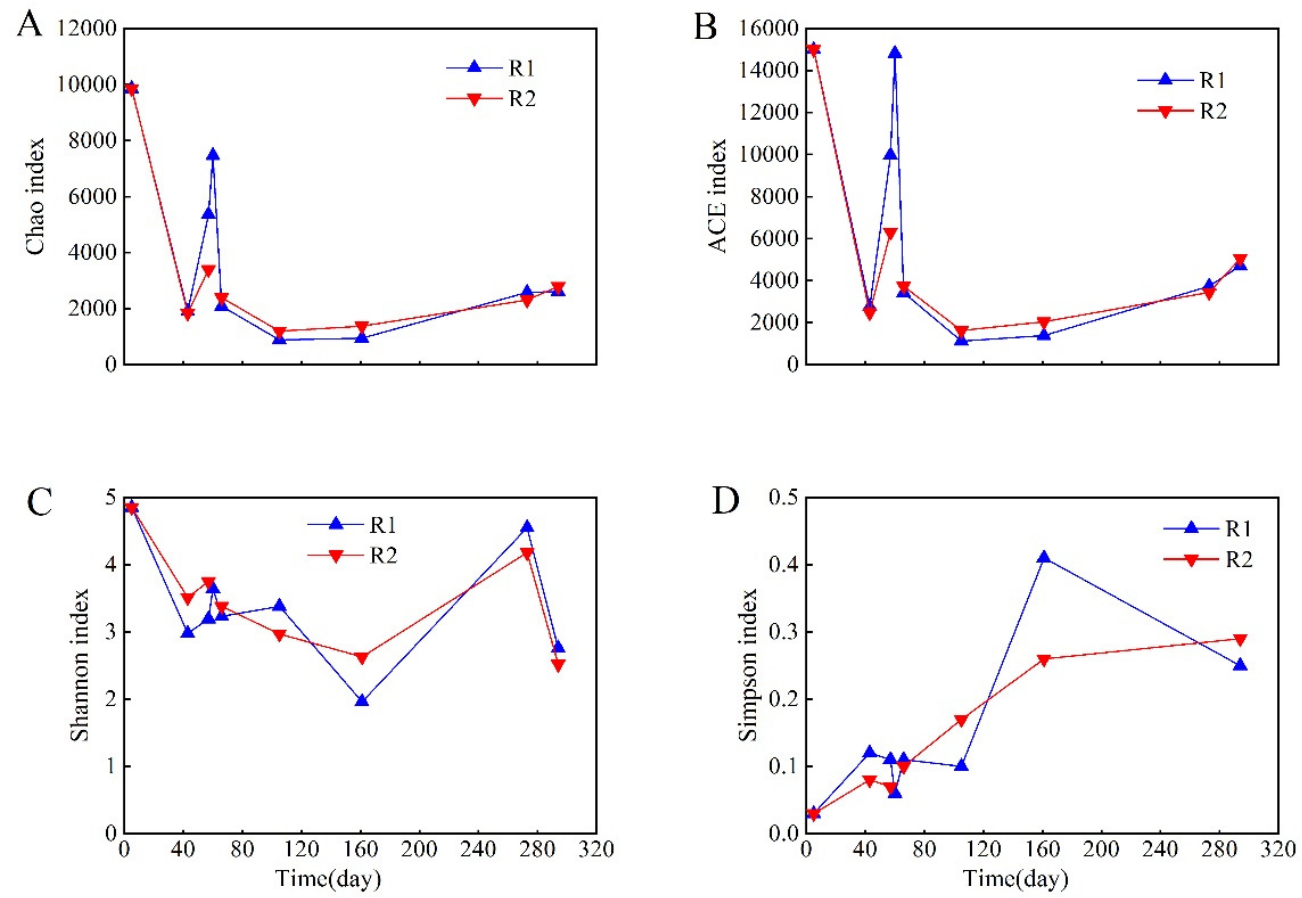

Figure 6. Richness and diversity indices of microbial populations in sewage sludge over the entire operating period in R1 and R2. (A) Chao1; (B) ACE; (C) Shannon; (D) Simpson.

It can be seen that there was no obvious difference in terms of the richness of the microbial population in both reactors during the different phases of operation. In addition, it was found that the richness of the microbial population decreased sharply after the formation of the aerobic granules, although there was a small fluctuation before the aerobic granules became dominant. The richness of the microbial population remained at its lowest level during the maturation period of the aerobic granules. After the maturation period, microbial richness increased slightly, but was still far below that of the original microbial population in the inoculum.

The Shannon and Simpson indices, which are positively and negatively related to diversity, respectively, are standard indicators of microbial diversity [15]. The Shannon index decreased during aerobic granule formation and maturation and recovered somewhat after maturation, while the Simpson index showed the opposite trend. All the indices shown in Figure 4 indicate that the richness and diversity of the microbial population decreased sharply during the formation of aerobic granules due to the selection of granule-favoring microbial populations and the leaching of flocs-favoring microbial populations, while it increased slightly during long-term maintenance due to the embedding and growth of more species in the granules. The coverage rate of the detected genera was 0.99 for both reactors, indicating the high credibility of the statistical data obtained from the microbial analysis of the aerobic granule samples.

\subsection{Microbial Population Dynamics and the Predominant Functional Groups}

Tracking the microbial composition of aerobic granules at various stages of growth and development can provide important information for identifying key microbial organisms and their associated specialized functions in aerobic granules, which could be used as meaningful indicators for monitoring and controlling the operating process. Tables 1 and 2 
show the main composition of the microbial populations in R1 and R2, respectively, during the entire operating period. A significant shift in microbial structure from the inoculum to the stable granule was observed, which was consistent with the report of aerobic granule microbial population dynamics during the start-up and steady state [18]. In addition, it is clear that the dominant genera in the two reactors are quite similar on the different days of operation, although the abundance of each genus is different. This indicates that the microbial structure in aerobic granules with small average size is determined by the operating conditions, which can be duplicated by setting the same operating parameters. Of all the genera of aerobic granules identified in Tables 1 and 2, most microbial organisms have at least one of the functions of EPS excretion, nitrification, denitrification, and organic matter degradation. EPS excretion is one of the most important microbial properties in granules, which can help microbial organisms aggregate and maintain a stable structure during long-term operation. Denitrifying bacteria or slow-growing autotrophic nitrifying bacteria promote a dense structure of aerobic granules by minimizing overgrowth of more general heterotrophic organisms that hinder aerobic granule formation and performance by promoting loosely structured flocs rather than compact granules [11]. A comparison with the predominant genera in the inoculum also shows that most of the bacteria in the aerobic granules originated from the genera in the inoculum during the formation and growth periods, and only 5 of the total 30 genera in the aerobic granules were new. This could show that most of the microbial genera in the aerobic granules are not exclusive and can be selected and enriched from the inoculated activated sludge.

Table 1. Predominant microbial genera in R1.

\begin{tabular}{|c|c|c|c|c|c|c|c|}
\hline \multirow{2}{*}{ Genus } & \multicolumn{7}{|c|}{ Operation Day } \\
\hline & 1 & 43 & 74 & 105 & 161 & 273 & 294 \\
\hline Alkanindiges & $6.88 \%$ & & & & & & \\
\hline Dechloromonas & $4.57 \%$ & $26.43 \%$ & $1.95 \%$ & $0.45 \%$ & $0.15 \%$ & $0.05 \%$ & $0.11 \%$ \\
\hline Acidovorax & $1.52 \%$ & & & $0.31 \%$ & $0.66 \%$ & $0.86 \%$ & $1.53 \%$ \\
\hline Stenotrophomonas & $2.72 \%$ & $0.03 \%$ & & & & & \\
\hline Propionivibrio & $1.94 \%$ & & & & & & $0.04 \%$ \\
\hline Nitrosomonas & $1.63 \%$ & & $4.25 \%$ & $3.09 \%$ & $0.15 \%$ & & $0.23 \%$ \\
\hline Flavobacterium & $1.61 \%$ & $0.42 \%$ & $0.09 \%$ & $0.1 \%$ & $0.06 \%$ & $0.22 \%$ & $0.05 \%$ \\
\hline Thauera & $0.13 \%$ & $21.6 \%$ & $5.69 \%$ & $16.06 \%$ & $5.20 \%$ & $0.04 \%$ & $0.12 \%$ \\
\hline Zoogloea & $0.38 \%$ & $8.15 \%$ & $18.32 \%$ & $26.00 \%$ & $64.26 \%$ & $11.9 \%$ & $50.13 \%$ \\
\hline Sideroxydans & & $3.99 \%$ & & $0.02 \%$ & & $0.14 \%$ & \\
\hline Bdellovibrio & $0.11 \%$ & $1.69 \%$ & $0.96 \%$ & $0.26 \%$ & $0.08 \%$ & $0.10 \%$ & \\
\hline Ferruginibacter & $0.26 \%$ & $1.07 \%$ & $0.66 \%$ & $0.39 \%$ & $0.11 \%$ & $1.58 \%$ & $0.95 \%$ \\
\hline Simplicispira & $0.05 \%$ & $0.64 \%$ & $0.05 \%$ & & & $0.01 \%$ & $0.03 \%$ \\
\hline Phreatobacter & & $0.12 \%$ & $0.14 \%$ & $0.06 \%$ & $0.01 \%$ & & \\
\hline Prosthecobacter & & & $3.43 \%$ & $2.57 \%$ & $1.16 \%$ & $2.76 \%$ & $1.1 \%$ \\
\hline Aquimonas & & $0.83 \%$ & $1.24 \%$ & $0.37 \%$ & $0.05 \%$ & & \\
\hline Sphingopyxis & & & $1.8 \%$ & $1.02 \%$ & & $0.04 \%$ & $0.01 \%$ \\
\hline Chryseolinea & $0.05 \%$ & $0.33 \%$ & $2.64 \%$ & $2.26 \%$ & $0.18 \%$ & $0.83 \%$ & $0.42 \%$ \\
\hline Terrimonas & $0.45 \%$ & $0.57 \%$ & $0.75 \%$ & $0.3 \%$ & $0.32 \%$ & $1.03 \%$ & $0.48 \%$ \\
\hline Lacibacter & $0.05 \%$ & & & $0.06 \%$ & $0.04 \%$ & $0.01 \%$ & \\
\hline Azoarcus & & $0.06 \%$ & $0.74 \%$ & $2.08 \%$ & $0.03 \%$ & $0.72 \%$ & $0.09 \%$ \\
\hline Phaeodactylibacter & $0.04 \%$ & & & $4.83 \%$ & & $0.12 \%$ & \\
\hline Ohtaekwangia & $0.02 \%$ & & $0.11 \%$ & $0.55 \%$ & $1.09 \%$ & $8.67 \%$ & $2.61 \%$ \\
\hline Aggregicoccus & $0.11 \%$ & $0.01 \%$ & $0.02 \%$ & $0.04 \%$ & $0.13 \%$ & $0.04 \%$ & \\
\hline Chryseobacterium & $0.04 \%$ & & $0.26 \%$ & $0.01 \%$ & $0.36 \%$ & $2.65 \%$ & $5.63 \%$ \\
\hline Nitrospira & $0.47 \%$ & & $0.01 \%$ & $0.01 \%$ & $0.41 \%$ & $4.06 \%$ & $0.76 \%$ \\
\hline Taibaiella & $0.98 \%$ & & & & $0.36 \%$ & $2.43 \%$ & $10.68 \%$ \\
\hline Tahibacter & $0.01 \%$ & $0.01 \%$ & $0.13 \%$ & $0.14 \%$ & $0.42 \%$ & $4.21 \%$ & $2.33 \%$ \\
\hline Sediminibacterium & $0.01 \%$ & $0.13 \%$ & $0.49 \%$ & $0.27 \%$ & $0.01 \%$ & $1.32 \%$ & $0.49 \%$ \\
\hline Luteimonas & $0.06 \%$ & $0.04 \%$ & & & & $0.1 \%$ & $0.38 \%$ \\
\hline
\end{tabular}


Table 2. Predominant microbial genera in R2.

\begin{tabular}{|c|c|c|c|c|c|c|c|}
\hline \multirow{2}{*}{ Genus } & \multicolumn{7}{|c|}{ Operation Day } \\
\hline & 1 & 43 & 74 & 105 & 161 & 273 & 294 \\
\hline Alkanindiges & $6.88 \%$ & & & & & & \\
\hline Dechloromonas & $4.57 \%$ & $26.01 \%$ & $2.2 \%$ & $1.11 \%$ & $0.43 \%$ & $0.02 \%$ & $0.10 \%$ \\
\hline Acidovorax & $1.52 \%$ & & & $0.64 \%$ & $1.13 \%$ & $0.76 \%$ & $1.22 \%$ \\
\hline Stenotrophomonas & $2.72 \%$ & $0.02 \%$ & & & & & \\
\hline Propionivibrio & $1.94 \%$ & & & & & & $0.03 \%$ \\
\hline Nitrosomonas & $1.63 \%$ & & $5.45 \%$ & $5.84 \%$ & $0.66 \%$ & & $0.24 \%$ \\
\hline Flavobacterium & $1.61 \%$ & $0.22 \%$ & $0.24 \%$ & $0.45 \%$ & $0.29 \%$ & $0.76 \%$ & $0.05 \%$ \\
\hline Thauera & $0.13 \%$ & $3.9 \%$ & $4.96 \%$ & $6.59 \%$ & $2.19 \%$ & $0.01 \%$ & $0.07 \%$ \\
\hline Zoogloea & $0.38 \%$ & $8.53 \%$ & $26.11 \%$ & $38.93 \%$ & $60.09 \%$ & $21.13 \%$ & $54.16 \%$ \\
\hline Sideroxydans & & $3.81 \%$ & & $0.01 \%$ & & $0.06 \%$ & \\
\hline Bdellovibrio & $0.11 \%$ & $2.09 \%$ & $0.26 \%$ & $1.10 \%$ & $0.06 \%$ & $0.13 \%$ & $0.01 \%$ \\
\hline Ferruginibacter & $0.26 \%$ & $1.19 \%$ & $0.38 \%$ & $0.08 \%$ & $0.04 \%$ & $1.26 \%$ & $0.86 \%$ \\
\hline Simplicispira & $0.05 \%$ & $2.11 \%$ & $0.08 \%$ & & & $0.01 \%$ & $0.01 \%$ \\
\hline Phreatobacter & & $1.53 \%$ & $0.16 \%$ & $0.16 \%$ & $0.01 \%$ & $0.02 \%$ & \\
\hline Prosthecobacter & & & & & $1.89 \%$ & $2.4 \%$ & $1.01 \%$ \\
\hline Aquimonas & & $0.07 \%$ & $1.5 \%$ & $0.81 \%$ & $0.51 \%$ & & \\
\hline Sphingopyxis & & & $0.44 \%$ & $0.10 \%$ & $0.07 \%$ & $0.07 \%$ & \\
\hline Chryseolinea & $0.05 \%$ & $1.17 \%$ & $3.97 \%$ & $2.30 \%$ & $1.04 \%$ & $0.14 \%$ & $0.03 \%$ \\
\hline Terrimonas & $0.45 \%$ & $0.81 \%$ & $1.43 \%$ & $0.97 \%$ & $0.1 \%$ & $2.34 \%$ & $0.43 \%$ \\
\hline Lacibacter & $0.05 \%$ & & & $3.82 \%$ & $3.64 \%$ & $0.05 \%$ & \\
\hline Azoarcus & & $0.44 \%$ & $0.31 \%$ & $1.92 \%$ & $0.06 \%$ & $0.29 \%$ & $0.1 \%$ \\
\hline Phaeodactylibacter & $0.04 \%$ & $0.01 \%$ & & $0.14 \%$ & & $0.06 \%$ & \\
\hline Ohtaekwangia & $0.02 \%$ & & & $0.02 \%$ & $0.28 \%$ & $2.96 \%$ & $2.71 \%$ \\
\hline Aggregicoccus & $0.11 \%$ & $0.17 \%$ & $0.01 \%$ & & $1.04 \%$ & & \\
\hline Chryseobacterium & $0.04 \%$ & & $0.19 \%$ & $0.29 \%$ & $0.02 \%$ & $5.26 \%$ & $6.02 \%$ \\
\hline Nitrospira & $0.47 \%$ & $0.07 \%$ & $0.01 \%$ & & $0.01 \%$ & $2.08 \%$ & $0.55 \%$ \\
\hline Taibaiella & $0.98 \%$ & & & & $0.09 \%$ & $2.45 \%$ & $10.58 \%$ \\
\hline Tahibacter & $0.01 \%$ & $0.03 \%$ & $0.36 \%$ & $0.03 \%$ & $0.1 \%$ & $0.01 \%$ & $1.79 \%$ \\
\hline Sediminibacterium & $0.01 \%$ & $0.07 \%$ & $0.56 \%$ & $0.35 \%$ & $0.02 \%$ & $0.07 \%$ & $0.34 \%$ \\
\hline Luteimonas & $0.06 \%$ & $0.06 \%$ & & & & $2.54 \%$ & $0.38 \%$ \\
\hline
\end{tabular}

The microbial genera from the inoculum that persisted and thrived in the aerobic granules can be characterized by their good aggregation ability combined with a short settling time. Among these species, Zoogloea, Thauera, and Dechloromonas were predominant and had a high percentage in the different stages of the sludge in both reactors (R1, R2). Zoogloea is much more abundant in the aerobic granules than Thauera and Dechloromonas, which increased significantly from $0.38 \%$ in the inoculum to over $50 \%$ in the granules at the end of the operation in both reactors, although there were fluctuations in the long-term maintenance of the aerobic granules. Zoogloea is a filamentous denitrifier that improves sludge adhesion and hydrophobicity by secreting EPS, thereby promoting microbial aggregation and granule stability [19]. Consequently, it becomes obvious that Zoogloea in aerobic granules play an important role in the formation and long-term stability of aerobic granules. Thus, Zoogloea can be considered as one of the major indicators of the stability of long-term operation of aerobic granule system for wastewater treatment with low strength and $\mathrm{C} / \mathrm{N}$ ratio. Thauera is also a typical denitrifier with the ability to excrete EPS in an aerobic granule system [20]. The abundance of Thauera gradually increased from $0.13 \%$ in the inoculum to maxima of $21.6 \%$ in R1 and $6.59 \%$ in R2, respectively, during the formation and maturation phases of the aerobic granule, but declined sharply to a level similar to that of the inoculum during long-term maintenance of the aerobic granules. Therefore, it can be hypothesized that Thauera is a very important functional genus for the formation and maturation of aerobic granules, but an unimportant functional genus for maintaining the long-term operation of the aerobic granular system. From the comparison of the abundance of Thauera in the two reactors, it can be seen that the abundance of Thauera in the granules in R2 with a much looser structure and a longer formation time was much lower than 
in R1. This confirms that Thauera plays a key role in the formation and maturation of the aerobic granules, the abundance of which determines the compactness of the aerobic granules and the rate of formation of the aerobic granules. In addition, Dechloromonas was found to be transiently abundant at $26.43 \%$ in R1 and $26.01 \%$ in R2 on day 43 , when sludge bulking occurred in both reactors. After the aerobic granules were formed, the abundance decreased sharply and remained at a much lower level than in the inoculum $(4.57 \%)$ during the remaining days of operation. Dechloromonas is a type of denitrifier with the ability to reduce nitrate to nitrite. The huge accumulation of Dechloromonas in the sludge bulking and the decrease in the established aerobic granule system indicate that Dechloromonas is closely related to the sludge formation and plays an unimportant role in the formation and maintenance of aerobic granules.

It should be noted that some genera, including Ohtaekwangia, Chryseobacterium, Taibaiella, and Tahibacter, had very low abundance during most of the operating time, but had relatively higher abundance during longer operation of the mature aerobic granules. The abundance of these bacteria ranged from 2 to $10 \%$ in both reactors, compared to the low abundance of 0.01 to $0.5 \%$ during most of the operating time. Ohtaekwangia has been described as a type of structure-forming bacteria in aerobic granules that excrete EPS and whose abundance increases with the growth of aerobic granules [7]. As reported, Chryseobacterium can live in a nutrient-poor environment [21]. Although a low organic concentration and a high ammonium concentration were used in this study, the low F/M in the long-term maintenance phase of the aerobic granules actually resulted in a nutrient-poor environment. This could explain the existence of Chryseobacterium in the aerobic granules. Tahibacter and Taibaiella are both aerobic, and it has been reported that they can reduce nitrate to nitrite [22] and nitrate to gaseous nitrogen [23], respectively. Their increased abundance may indicate that they play an important role in denitrification in the longterm maintenance phase of aerobic granules. Thus, from the above, it is clear that these genera perform different functions in aerobic granules, and their structure supports their proliferation and accumulation in the granules during the long-term maintenance phase.

In addition, there were also some microbial genera such as Acidovorax, Bdellovibrio, Ferruginibacter, Terrimonas, and Chryseolinea which showed very low abundance throughout the entire operating period. Their abundances were less than $2 \%$, indicating that they may play an unimportant role in the aerobic granules. Upon closer inspection, it turns out that these bacteria are all heterotrophic, but have several adaptive characteristics that allow them to live in aerobic granular sludge. Specifically, Acidovorax is a type of facultative denitrifier that occurs in low-COD conditions [24,25] and is able to self-aggregate and produce EPS. Bdellovibrio is aerobically heterotrophic and occurs in well-treated wastewater where it is able to prey on Gram-negative bacteria and utilize COD such as polymers, and ammonium [26]. Ferruginibacter and Terrimonas can degrade organic matter and excrete EPS for better sludge aggregation $[27,28]$. Chryseolinea can degrade small organic molecules as well as large polymers such as proteins and polysaccharides [29]. Of all the genera identified in Tables 1 and 2, Nitrosomonas and Nitrospira are the ammonia-oxidizing bacteria in R1 and R2 that originated from the inoculum and remained in the aerobic granules throughout the operating period. The abundance of the two types of bacteria showed opposite development trends during operation. Nitrosomonas was more abundant in the newly formed aerobic granules, with a maximum of $4.25 \%$ in R1 and 5.84\% in R2, respectively, while its abundance was very low in the long-term maintenance phase. Conversely, the abundance of Nitrospira was higher in the long-term maintenance phase, with a maximum of $4.06 \%$ in $\mathrm{R} 1$ and $2.08 \%$ in $\mathrm{R} 2$, respectively, but a very low abundance in the granule formation phase. This is due to the different ammonium affinity of the two bacteria, which determines their proliferation and accumulation in the stages with different available ammonium concentrations. Nitrosomonas tends to grow at high ammonium concentrations but is inhibited by low ammonium concentrations, while Nitrospira is adaptive only to conditions of low ammonium concentration. In both R1 and R2, although the ammonium concentrations in the influent were constant throughout the operating period, the F/M 
of ammonium changed greatly due to the development of biomass, with MLSS ranging from less than $1 \mathrm{~g} / \mathrm{L}$ to about $6 \mathrm{~g} / \mathrm{L}$. During the formation phase of the aerobic granules, the F/M of ammonium was comparatively high with extremely low MLSS, while after the maturation phase, the $\mathrm{F} / \mathrm{M}$ of ammonium was comparatively low due to the highly accumulated biomass in the reactors. This explains well why Nitrosomonas predominated during the period of aerobic granule formation when the ammonium concentration was relatively high for a long time, while Nitrospira predominated after the maturation of aerobic granules when the ammonium concentration in the microenvironment was lower.

In addition to the above genera that originated from the inoculum, there were some bacteria that were not detectable in the inoculum but that formed during granule formation. These were Sideroxydans, Phreatobacter, Prosthecobacter, Aquimonas, Sphingopyxis, and Azoarcus. The abundance of these bacteria was less than $3.5 \%$ in R1 and R2, but they were present in different stages of aerobic granule formation, showing the possible role of each bacterium in the corresponding stages. In particular, Phreatobacter accounted for $3.43 \%$ and $2.76 \%$ in aerobic granules at days 76 and 273 in R1, respectively, while it accounted for $2.4 \%$ at day 273 but did not appear in R2 until after 161. Phreatobacter is a strictly aerobic, oligotrophic denitrifier capable of excreting extracellular protein for sludge aggregation [30,31]. Its presence in the maturation and long-term maintenance phases of aerobic granules in R1 and R2 may indicate that it is particularly adapted to the long-term maintenance environment. Moreover, Azoarcus occurred in all stages of aerobic granules since its first appearance on day 43 in both R1 and R2. Azoarcus is a denitrifier similar to Thauera [32,33], but may play only a minor role in aerobic granules at such low abundance.

\subsection{Food to Microbial Biomass Ratio (F/M) and its Relationship with the Predominant Genus in} the Aerobic Granules

Food-to-microbial biomass ratio $(\mathrm{F} / \mathrm{M})$ is the biomass loading rate, which refers to the substrate loading per unit biomass in a unit time for wastewater treatment. In the aerobic granular sludge system, F/M affects the average available substrate in the microenvironment, which could influence the microbial growth of the aerobic granules. From Figure 7, F/M is high during aerobic granule formation, while it decreases sharply during maturation and remains at a very low level in the long-term maintenance phase. Specifically, F/M increased to $1.83 \mathrm{~g}$ COD/g VSS-d at the maximum in formation and remained in a narrow range of $0.2-0.4 \mathrm{~g}$ COD/g VSS-d in the long-term maintenance of aerobic granules in R1; whereas F/M increased to $2.90 \mathrm{~g}$ COD/g VSS- $\mathrm{d}$ at the maximum in formation and remained in the same range as in $\mathrm{R} 1$ in the long-term maintenance of aerobic granules in $\mathrm{R} 2$. The changing trends of $\mathrm{F} / \mathrm{M}$ are consistent with the previous assumption that high F/M stimulates the formation while low $\mathrm{F} / \mathrm{M}$ maintains the long-term stability of aerobic granules [8]. In addition, it is noted that the much higher F/M in R2 causes a much longer formation time than in R1, which may indicate that there may be a suitable range of $\mathrm{F} / \mathrm{M}$ for a better balance between formation stimulation and formation rate of aerobic granules.

$\mathrm{F} / \mathrm{M}$ was the main variable in the operation as other adjustable operating parameters were set unchanged in this study. The change of $\mathrm{F} / \mathrm{M}$ in the operation period may lead to changes in the microenvironment of the bioprocess and thus to the response of the predominant bacteria. In order to clarify the role of the predominate bacteria in the bioprocess, the relationship between $\mathrm{F} / \mathrm{M}$ and the predominant bacteria during the whole operation period was analyzed as shown in Figure 8. From Figure 8A,B, it can be seen that denitrifier Zoogloea is one of the most predominant genera throughout the whole F/M range while it is an absolutely dominant genus when the F/M was below 0.6 in both R1 and R2. Denitrifier Thauera and Dechloromonas are adaptive to the high F/M range but cannot survive in the low F/M range, especially for Dechloromonas, which presented as a transit. Based on the characteristics of these genera, it can be assumed that Zoogloea has a fundamental role in the aerobic granules, whereas Thauera plays important roles at high F/M values due to their great ability for EPS excretion. Dechloromonas may play 
unimportant roles in aerobic granules due to inability for EPS excretion, though they are active at high F/M values. Conversely, Ohtaekwangia, Chryseobacterium, and Taibaiella are only adaptive in the low-F/M ranges, which might be connected with their ability for EPS excretion, adaption to nutrient-deficient environment, and aerobic denitrification, respectively. Besides, ammonia-oxidation and nitrification are also very important metabolism processes in the aerobic granules, with Nitrosomonas in dominance in the high F/M ranges while Nitrospira in dominance in the low F/M ranges. In addition, from Figure $8 \mathrm{C}, \mathrm{D}$, it can be seen that some genera with very low abundance could contribute to the diversity of the microbial community in the aerobic granules, but their microbial functions are unclear.
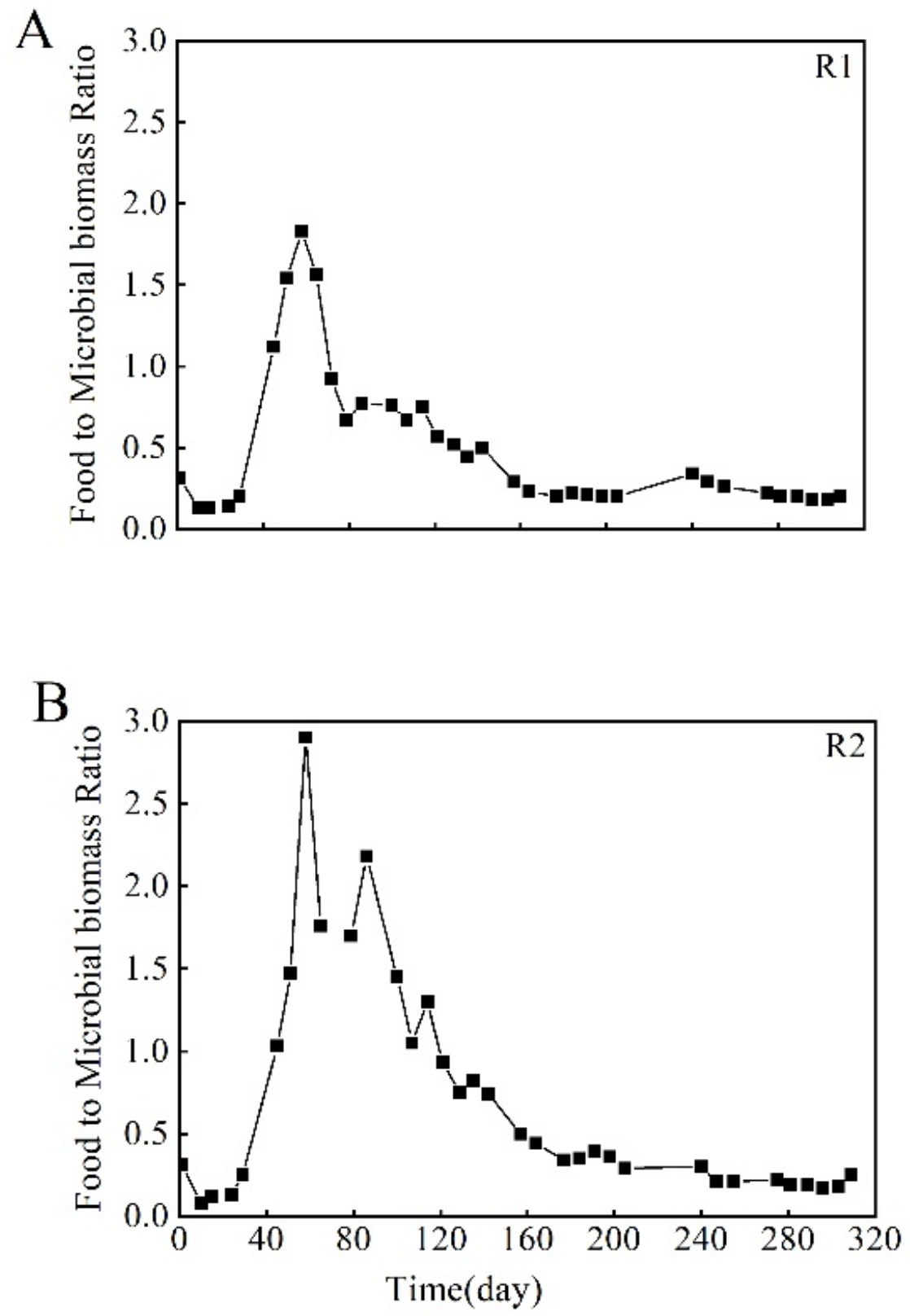

Figure 7. Food-to-Microbial Biomass Ratio in the whole operation period. (A) R1; (B) R2. 

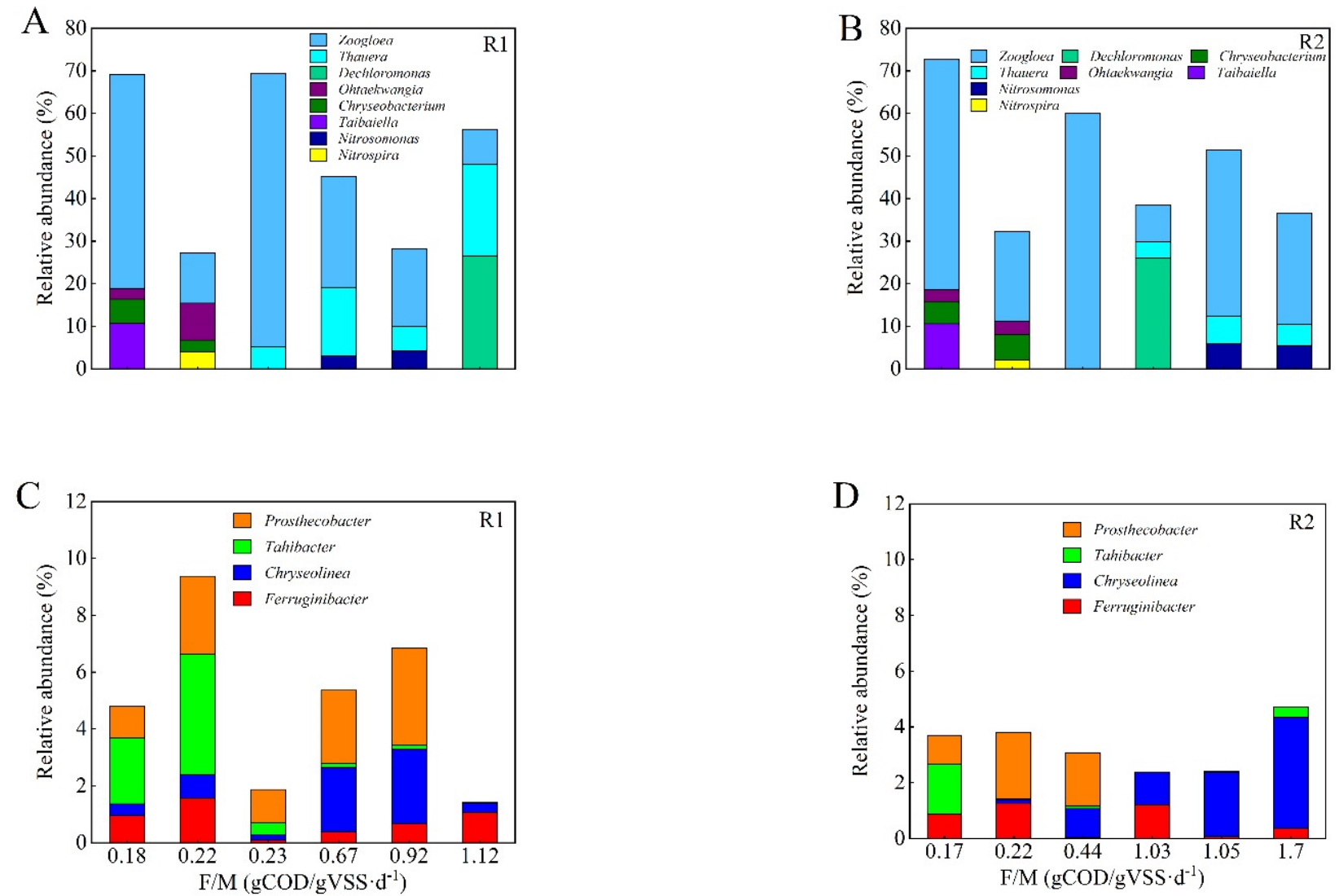

Figure 8. The relationship between $\mathrm{F} / \mathrm{M}$ and the relative abundance of the predominant genus in the aerobic granules in R1 and R2. (A,B), genera with maximum relative abundance higher than $5 \%$ in $\mathrm{R} 1$ and R2, respectively; (C,D), genera with maximum relative abundance lower than $5 \%$ in $\mathrm{R} 1$ and $\mathrm{R} 2$, respectively.

\section{Conclusions}

In this study, two parallel aerobic granular sludge SBR reactors, R1 and R2, were operated for the treatment of synthetic wastewater with a COD concentration of $400 \mathrm{mg} / \mathrm{L}$ and a chemical-oxygen-demand-to-nitrogen $(\mathrm{COD} / \mathrm{N})$ ratio of 4:1 under anoxic-oxic conditions. All other operating conditions were also identical. The main conclusions are as follows.

- The $\mathrm{SVI}_{30}$ before and during granulation was different in the two reactors, although it reached similar values after granule maturation. In addition, the mean size and size distribution of the sludge were quite different in the two reactors, although both reactors were operated under exactly the same conditions. These differences indicate some degree of randomness in granule formation and size development even under identical conditions. However, the similarity of the physicochemical and microbial properties of the granules, as well as the performance of the wastewater treatment after granule maturation, indicate that the operating conditions can produce consistent results, implying predictability of stable operation in practice.

- A high $\mathrm{F} / \mathrm{M}$ value promotes the formation of aerobic granules, while a low F/M value in the range of $0.2-0.4 \mathrm{~g}$ COD/g VSS $\mathrm{d}$ facilitates the long-term stability of aerobic granules.

- The richness of the microbial population of the granules was much lower than that of the inoculum and the flocs with bulking, although the richness may increase slightly during the long-term operation period. The diversity of the microbial structure decreased over time. However, the reduction in the richness and diversity of the microbial population due to the conversion of flocs to granules did not affect the wastewater 
treatment performance and long-term stability of the sludge, indicating the robustness of different microbial structures to achieve the same function in wastewater treatment.

- Among the dominant genera of the sludge, Zoogloea played a key role in maintaining the stable structure of aerobic granules throughout the operation period, while Thauera is an important genus for the formation and maturation of aerobic granules, but not for long-term maintenance. In addition, Ohtaekwangia, Chryseobacterium, Taibaiella, and Tahibacter can play an important role in the long-term stability of aerobic granules.

These results demonstrate the reproducibility of granulation, the small influence of granulation on long-term stability, and the robustness of aerobic granulation for the removal of COD and N. Overall, our study contributes significantly to the understanding of microbial community structure for the long-term stability of aerobic granular sludge in the treatment of low-COD and low-COD/N-ratio wastewater in practice.

Author Contributions: Conceptualization, F.C. and Y.-Q.L.; methodology, H.Z. and S.M.; validation, F.C. and Y.-Q.L. and Sternberg, C.E.W.S.; formal analysis, H.Z. and S.M.; investigation, H.Z., S.M. and W.D.; data curation, H.Z.; writing-original draft preparation, H.Z. and F.C.; writing-review and editing, F.C., Y.-Q.L. and C.E.W.S.; supervision, F.C.; project administration, S.M. and W.D.; funding acquisition, F.C. All authors have read and agreed to the published version of the manuscript.

Funding: This research was funded by the National Nature Science Foundation of China (grant number 41763016).

Informed Consent Statement: Information consent was obtained from all subjects involved in the study.

Conflicts of Interest: The authors declare no conflict of interest.

\section{References}

1. Wang, L.; Liu, X.; Lee, D.-J.; Tay, J.-H.; Zhang, Y.; Wan, C.-L.; Chen, X.-F. Recent advances on biosorption by aerobic granular sludge. J. Hazard. Mater. 2018, 357, 253-270. [CrossRef] [PubMed]

2. Lee, D.-J.; Chen, Y.-Y.; Show, K.-Y.; Whiteley, C.G.; Tay, J.-H. Advances in aerobic granule formation and granule stability in the course of storage and reactor operation. Biotechnol. Adv. 2010, 28, 919-934. [CrossRef] [PubMed]

3. Liu, Y.; Liu, Q.S. Causes and control of filamentous growth in aerobic granular sludge sequencing batch reactors. Biotechnol. Adv. 2006, 24, 115-127. [CrossRef] [PubMed]

4. Bengtsson, S.; de Blois, M.; Wilen, B.-M.; Gustavsson, D. Treatment of municipal wastewater with aerobic granular sludge. Crit. Rev. Environ. Sci. Technol. 2018, 48, 119-166. [CrossRef]

5. Adav, S.S.; Lee, D.-J.; Show, K.-Y.; Tay, J.-H. Aerobic granular sludge: Recent advances. Biotechnol. Adv. 2008, 26, 411-423. [CrossRef]

6. Cydzik-Kwiatkowska, A.; Wojnowska-Barya, I. Nitrogen-converting communities in aerobic granules at different hydraulic retention times (HRTs) and operational modes. World J. Microbiol. Biotechnol. 2015, 31, 75-83. [CrossRef]

7. Swiatczak, P.; Cydzik-Kwiatkowska, A. Performance and microbial characteristics of biomass in a full-scale aerobic granular sludge wastewater treatment plant. Environ. Sci. Pollut. Res. 2018, 25, 1655-1669. [CrossRef]

8. Cha, L.; Liu, Y.-Q.; Duan, W.; Sternberg, C.E.W.; Yuan, Q.; Chen, F. Fluctuation and Re-Establishment of Aerobic Granules Properties during the Long-Term Operation Period with Low-Strength and Low C/N Ratio Wastewater. Process 2021, 9, 1290. [CrossRef]

9. $\quad$ Pronk, M.; de Kreuk, M.K.; de Bruin, B.; Kamminga, P.; Kleerebezem, R.; van Loosdrecht, M.C.M. Full scale performance of the aerobic granular sludge process for sewage treatment. Water Res. 2015, 84, 207-217. [CrossRef]

10. Yang, S.F.; Tay, J.H.; Liu, Y. Effect of substrate nitrogen/chemical oxygen demand ratio on the formation of aerobic granules. J. Environ. Eng. 2005, 131, 86-92. [CrossRef]

11. de Kreuk, M.K.; Kishida, N.; Tsuneda, S.; van Loosdrecht, M.C.M. Behavior of polymeric substrates in an aerobic granular sludge system. Water Res. 2010, 44, 5929-5938. [CrossRef] [PubMed]

12. Layer, M.; Adler, A.; Reynaert, E.; Hernandez, A.; Pagni, M.; Morgenroth, E.; Holliger, C.; Derlon, N. Organic substrate diffusibility governs microbial community composition, nutrient removal performance and kinetics of granulation of aerobic granular sludge. Water Res. X 2019, 4, 100033. [CrossRef] [PubMed]

13. Liu, Y.Q.; Liu, Y.; Tay, J.H. Relationship between size and mass transfer resistance in aerobic granules. Lett. Appl. Microbiol. 2005, 40, 312-315. [CrossRef] [PubMed]

14. APHA, Standard Methods for the Examination of Water and Wastewater, 23rd ed.; American Public Health Association, American Water Works Association, and Water Environmental Federation: Washington, DC, USA, 2017. 
15. Hill, T.C.J.; Walsh, K.A.; Harris, J.A.; Moffett, B.F. Using ecological diversity measures with bacterial communities. FEMS Microbiol. Ecol. 2003, 43, 1-11.

16. Westphal, C.; Bommarco, R.; Carré, G.; Lamborn, E.; Morison, N.; Petanidou, T.; Potts, S.G.; Roberts, S.P.M.; Szentgyörgyi, H.; Tscheulin, T.; et al. Measuring bee diversity in different European habitats and biogeographical regions. Ecol. Monogr. 2008, 78, 653-671. [CrossRef]

17. Liu, Y.-Q.; Tay, J.-H. The competition between flocculent sludge and aerobic granules during the long-term operation period of granular sludge sequencing batch reactor. Environ. Technol. 2012, 33, 2619-2626. [CrossRef]

18. Liu, Y.Q.; Kong, Y.H.; Zhang, R.; Zhang, X.; Wong, F.S.; Tay, J.H.; Zhu, J.R.; Jiang, W.J.; Liu, W.T. Microbial population dynamics of granular aerobic sequencing batch reactors during start-up and steady state periods. Water Sci. Technol. 2010, 62, 1281-1287. [CrossRef]

19. Wang, L.; Zhan, H.; Wang, Q.; Wu, G.; Cui, D. Enhanced aerobic granulation by inoculating dewatered activated sludge under short settling time in a sequencing batch reactor. Bioresour. Technol. 2019, 286, 121386. [CrossRef]

20. He, Q.; Chen, L.; Zhang, S.; Chen, R.; Wang, H. Hydrodynamic shear force shaped the microbial community and function in the aerobic granular sequencing batch reactors for low carbon to nitrogen $(\mathrm{C} / \mathrm{N})$ municipal wastewater treatment. Bioresour. Technol. 2019, 271, 48-58. [CrossRef]

21. Yoon, J.-H.; Kang, S.-J.; Oh, T.-K. Chryseobacterium daeguense sp nov., isolated from wastewater of a textile dye works. Int. J. Syst. Evol. Microbiol. 2007, 57, 1355-1359. [CrossRef]

22. Makk, J.; Homonnay, Z.G.; Keki, Z.; Lejtovicz, Z.; Marialigeti, K.; Sproeer, C.; Schumann, P.; Toth, E.M. Tahibacter aquaticus gen. nov., sp nov., a new gammaproteobacterium isolated from the drinking water supply system of Budapest (Hungary). Syst. Appl. Microbiol. 2011, 34, 110-115. [CrossRef] [PubMed]

23. Chhetri, G.; Kim, I.; Kim, J.; Kang, M.; Seo, T. Taibaiella lutea sp. nov., Isolated from Ubiquitous Weedy Grass. Curr. Microbiol. 2021, 78, 2799-2805. [CrossRef] [PubMed]

24. Gonzalez-Gil, G.; Holliger, C. Dynamics of microbial community structure of and enhanced biological phosphorus removal by aerobic granules cultivated on propionate or acetate. Appl. Environ. Microbiol. 2011, 77, 8041-8051. [CrossRef] [PubMed]

25. Ehsani, E.; Jauregui, R.; Geffers, R.; Jarek, M.; Boon, N.; Pieper, D.H.; Vilchez-Vargas, R. First Draft Genome Sequence of the Acidovorax caeni sp. nov. Type Strain R-24608 (DSM 19327). Genome Announc. 2015, 3, e01378-15. [CrossRef] [PubMed]

26. Feng, S.; Tan, C.H.; Constancias, F.; Kohli, G.S.; Cohen, Y.; Rice, S.A. Predation by Bdellovibrio bacteriovorus significantly reduces viability and alters the microbial community composition of activated sludge flocs and granules. FEMS Microbiol. Ecol. 2017, 93, fix020. [CrossRef] [PubMed]

27. Han, X.; Zhou, Z.; Mei, X.; Ma, Y.; Xie, Z. Influence of fermentation liquid from waste activated sludge on anoxic/oxic-membrane bioreactor performance: Nitrogen removal, membrane fouling and microbial community. Bioresour. Technol. 2018, 250, 699-707. [CrossRef]

28. Ummalyma, S.B.; Gnansounou, E.; Sukumaran, R.K.; Sindhu, R.; Pandey, A.; Sahoo, D. Bioflocculation: An alternative strategy for harvesting of microalgae-An overview. Bioresour. Technol. 2017, 242, 227-235. [CrossRef]

29. Yu, H.; Meng, W.; Song, Y.; Tian, Z. Understanding bacterial communities of partial nitritation and nitratation reactors at ambient and low temperature. Chem. Eng. J. 2017, 337, 755-763. [CrossRef]

30. Staley, J.T.; Bouzek, H.; Jenkins, C. Eukaryotic signature proteins of Prosthecobacter dejongeii and Gemmata sp Wa-1 as revealed by in silico analysis. FEMS Microbiol. Lett. 2005, 243, 9-14. [CrossRef]

31. Baek, K.; Choi, A. Complete Genome Sequence of Phreatobacter sp. Strain NMCR1094, a Formate-Utilizing Bacterium Isolated from a Freshwater Stream. Microbiol. Resour. Announc. 2019, 8, e00860-19. [CrossRef]

32. Raittz, R.T.; de Pierri, C.R.; Maluk, M.; Batista, M.B.; Carmona, M.; Junghare, M.; Faoro, H.; Cruz, L.M.; Battistoni, F.; Souza, E.D.; et al. Article comparative genomics provides insights into the taxonomy of Azoarcus and reveals separate origins of nif genes in the proposed Azoarcus and Aromatoleum genera. Genes 2021, 12, 71. [CrossRef] [PubMed]

33. Xi, L.; Liu, D.; Huang, W. Effect of acetate and propionate on the production and characterization of soluble microbial products (SMP) in aerobic granular sludge system. Toxicol. Environ. Chem. 2018, 100, 175-190. [CrossRef] 